Bright, S. and Kane, R. and Bishop, B.J. and Marsh, A. 2014. Development of the Australian Dominant Drug Discourses Scale. Addiction Research and Theory. 22 (5): pp. 416-423. 


\title{
DEVELOPMENT OF THE AUSTRALIAN DOMINANT DRUG DISCOURSES SCALE
}

\begin{abstract}
There are a limited number of dominant discourses available to frame drug use within Australia. These dominant discourses play an important role in policy debate and development, and also drug use behaviour. We describe the development of a psychometric instrument that is hypothesised to measure the degree to which individuals internalise dominant drug discourses. Sixty items were developed to reflect six dominant discourses of drug use. A substantive validity analysis was conducted. The highest loading items were included in a 27 item measure that was administered to 370 people seeking substance use treatment in Perth, Western Australia. In addition, participants completed the Locus of Control of Behaviour Scale. Confirmatory Factor Analysis tested the fit of a predicted six factor model, in addition to three other plausible models. The best fitting model was the predicted model. Internal locus of control was correlated with medical and legal discourse. The Dominant Drug Discourses Scale appears to measure internalisation of six dominant discourses. The tool has utility in research examining policy development and drug use behaviours. To establish the construct validity of the tool and better understand the constructs being measured validity, further research is required.
\end{abstract}

Key Words: Psychology, Sociology, Dominant Discourses, Psychometrics, Drugs

Word Count: 192 


\section{DEVELOPMENT OF THE AUSTRALIAN DOMINANT DRUG DISCOURSES SCALE}

Drugs can be conceptualised as social constructions. That is, while drugs have distinct objective pharmacological properties, a person's understanding of drugs is influenced by various institutional and individual actors within that person's culture, each of whom have particular interests and ideologies (Dingelstad, Gosden, Martin, \& Vakas, 1996). This process can be understood through the role of discourses, which have been broadly defined as linguist frameworks that provide specific subject positions and demarcate what narratives are coherent (Burr, 2003). Dominant discourses develop through symbiotic relationships with those institutions that hold power within a culture. Narratives that are coherently framed within the dominant discourses of a culture are perceived by individuals within that culture to hold the most 'truth' value. As such, dominant discourses limit what can be rationally thought, spoken and understood about drugs.

The dominant discourses within which drugs are framed in Australia typically only allow for pathological narratives. They are constructed as dangerous (Room, 2006), harmful (Lancaster \& Ritter, in press; Moore, 2008), corruptive and criminogenic (Stevens, 2007). Certain drugs might be ascribed more pathogenic agency than others. For example, Moore (2004) has highlighted how each drug is constructed as a subject with a distinct personality, or 'drugality'. Thus, while alcohol might be thought of as a larrikin, heroin is oppressive and crack is perverse. Within these pathogenic narratives, people who use drugs are afforded limited subject positions that typically provide minimal agency. For example, Barratt (2012) has highlighted how drug users in Australia are often incorrectly constructed as ignorant, irrational, and irresponsible. Meanwhile, Fraser and Moore (2008) have shown how drug users are constructed as chaotic and disordered.

Bright Marsh, Bishop and Smith (2008) undertook an analysis of Australian discourse through examining media reports involving alcohol and other drugs. They found that there were six dominant discourses available to frame alcohol and other drugs (an overview of these dominant discourses can be seen in Table 1). Medical, moral, legal and political discourses each provided space for specific pathological narratives. For example, Bright et al. (2008) noted that within medical discourse drugs are constructed as pathogens that reduce a drug user's agency, which can only be restored through relinquishing control to experts. While the dominant culture is protected against the pathogenic effects of alcohol, there are a minority of individuals who have some underlying vulnerability (e.g., indigenous, youth, etc.). In contrast, moral discourse was described as constructing drugs as corruptive and those that use them as deviants who are somehow weak-willed. Only economic and glamour discourses provided an opportunity for non-pathological narratives; however, Bright et al. noted that within the dominant culture, economic discourse was limited to framing alcohol while glamour discourse was only available to frame celebrity drug use.

It is essential that the dominant drug discourses be better understood for three reasons. First, drug research has a symbiotic relationship with dominant discourses. Research that most conforms to dominant discourses will attract the most funding. Consequently, most drug research has focused on the pathology of drug use, providing a skewed perspective of drugs and drug use (Mugford, 1991). In turn, this research reinforces the dominant discourses.

Second, a number of researchers (e.g., Bright, Bishop, Kane, Marsh, \& Barratt, 2013; Dingelstad et al., 1996; Duff, 2004; Elliott \& Chapman, 2000; Lancaster \& Ritter, in press; Lawrence, Bammer, \& Chapman, 2000; Stevens \& Ritter, in press) have demonstrated the influence of dominant discourses 
on drug policy. For example, the focus of any given policy debate is limited by the available dominant discourses. This is illustrated by the debate regarding cannabis, which tends to focus on its legal status based on varying accounts of its harm potential. The research that is used to develop policy is often conducted within the context of dominant discourses. Further, dominant discourses limit the scope of drug policy development. For example, because pathogenic narratives cannot coherently acknowledge pleasure, the notion of moderation (or controlled drug use) cannot be rationally discussed since any drug use is undesirable. In turn, this precludes strategies encouraging moderate drug consumption being implemented.

Third, dominant discourses influence people's drug use behaviour and treatment seeking. This occurs indirectly through the implementation of policies that are necessarily developed within the context dominant discourses, and also directly through a process of internalisation. By doing so, drug users' attributions regarding their drug-related behaviours are framed by the available narratives and subject position in a similar manner to the self-stereotyping originally described by Hogg and Turner (1987). For example, internalisation of moral discourse would lead drug users to identify with the deviant subject position and perhaps increase the degree of stigma that they perceive. Perceptions of stigma among drug users have been found to be associated with reduced access to healthcare, increased experiences of discrimination and poorer mental health (Ahern, Stuber, \& Galea, 2007).

Similarly, individuals that internalise medical discourse will identify with the subject position of the "addict" and thus might be more likely to have an external locus of control. Therapists from a range of perspectives (e.g., Beatch et al., 2009; Teyber, 1997; Yalom, 2002) have contended successful behaviour change requires individuals to take personal responsibility for their behaviour. Hence, internalisation of medical discourse by individuals experiencing problems associated with their substance use could hinder their behaviour change efforts. However, Keene and Raynor (1993) found that internalisation of medical discourse, as evidenced by the degree to which participants endorsed the disease model of addiction, was associated with positive treatment outcomes in a 12step program. Similarly, Hammer, Dingel, Ostergren, Nowakowski, and Koenig (2012) found that many of the participants that they interviewed who were engaged in treatment believed that a genetic/medical understanding of their behaviour had utility in assisting their effects to change their behaviour. Hammer et al. (2012) noted a range of narratives that had diverse outcomes. Perhaps then, people who internalise certain dominant discourses might have better outcomes when they are matched to a particular treatment that shares this understanding of addictive behaviour.

To better understand the role of the dominant discourses regarding drugs, we sought to develop a psychometric instrument that measures the degree to which individuals internalise those discourses found by Bright et al. (2008) to be dominant within Australian society. Such an instrument might be used to further our understanding of how discourses are structured, and how they influence drug policy and clinical processes in treatment settings. Since some might consider the use of psychometric measurement to be incompatible with social constructionism, it is important the paradigmatic assumptions herewith are defined:

(i) The ontological perspective is that of critical realism, where multiple methods are necessarily utilised to capture an approximation of an unascertainable single objective reality (Nightingale \& Cromby, 1999; Parker, 1998). 
(ii) The epistemology is pragmatic, such that the pursuit of knowledge is problem-focused and

is directed by the anticipated consequences of pre-existing knowledge (Cherryholmes, 1992).

\section{METHOD}

\section{Item development}

In accordance with the procedure for psychometric item development outlined by Oppenheim, 60 items expressing "a point of view, a belief, a preference, a judgement, an emotional feeling, or a position for or against something" (1992, p. 174) were formulated for each of the six dominant discourses outlined by Bright et al. (2008). Each of the items included (either implicitly or explicitly) at least one of the subject positions inherent to the relevant discourse outlined by Bright et al. Given the neo-liberal nature of economic discourse, a personal subject position was trialled for some of these items. Each of the items additionally reflected a potential narrative that constructed drugs in a manner that would be congruent with the relevant discourse. Because more narratives were available within certain discourses (e.g., moral) than others (e.g., glamour), more items were generated for some discourses than others. In developing items, we aimed to minimise redundant items and statements susceptible to response bias (Murphy \& Davidshofer, 2005). The content validity of the items was established through refinement by a psychometrician and individuals working within the AOD field. The final 60 items that were developed is outlined in Table 1.

Substantive validity of the refined items was ascertained using the procedure outlined by Anderson and Gerbing (1991). Specifically, the 60 items were randomly placed in a questionnaire with the six discourses randomly assigned a number and briefly described at the start of the questionnaire. Twenty people seeking treatment at a Perth residential substance use treatment agency were provided with an information letter and the instrument (Anderson and Gerbing recommend a sample size of between 12 and 30 participants). Participants were instructed to participate they would be required to assign a number to each item that best reflected the corresponding discourse description (see Table 2). Consent to participant was implied through the anonymous return of the completed instrument. All instruments were returned completed.

Each item was analysed using Anderson and Gerbing's (1991) substantive-validity co-efficient: $c_{\mathrm{sv}}=n_{\mathrm{c}}$ $-n_{\mathrm{o}} / N$, where $n_{\mathrm{c}}$ represents the number of participants who endorse the presupposed dimension and $n_{0}$ represents the maximum number of participants who endorse a different dimension. The extent to which an item reflects a dimension can then be examined by performing a binomial test of significance. Items measuring the intended dimension are reflected by a probability of less than .05 , although Anderson and Gerbing note that in practice the items retained will often reflect those having the highest $c_{s v}$ values. At least four items were retained for each dimension. The retained items (see Appendix) were used to construct the Dominant Drug Discourses Scale (DDDS).

\section{Participants in the scale development}

The sample consisted of 192 male and 156 females aged between 16 - and 75-years $(M=37.50, S D=$ 10.78) who were seeking treatment at one of several substance use agencies in the northern 
suburbs of the Perth metropolitan area, in addition to 23 individuals who did not disclose their age or gender. The most common drug for which people were primarily seeking treatment was alcohol (39\%) followed by amphetamines (22\%), opiates (18\%), cannabis (5\%) and benzodiazepines (2\%). Fourteen percent of participants did not disclose the drug for which they were seeking treatment.

\section{Measures}

The level of agreement for each of the 27 items within the DDDS was rated on a 5-point Likert scale. In addition to the DDDS, participants were provided with Craig, Franklin and Andrews's (1984) Locus of Control of Behaviour Scale (LCBS). Since Confirmatory Factor Analysis (CFA) has shown the non reverse scored "internal items" are more robust than the reversed scored external items (Bright, Kane, Marsh, \& Bishop, 2013), only the internal items were included.

\section{Procedure}

Several Perth treatment agencies (excluding the agency involved in the substantive validity analysis study) were asked if they could provide clients with the measures and an information letter. Given that no identifying information was obtained, informed consent was implied by the anonymous return of the completed measures. Ethics approval was gained from both the Curtin University Human Research Ethics Committee (HREC) and the HRECs attached to each of the treatment agencies.

\section{Data analysis and model testing}

There were missing data for a total of 128 items across the 371 cases. Results from Little's Missing Completely At Random (MCAR) test, performed using SPSS 19, indicated that the pattern of missing item values did not statistically deviate from randomness. Missing values were subsequently imputed using the SPSS expectation maximisation algorithm.

Confirmatory factor analysis (CFA), as implemented through LISREL 8.8 (Jöreskog \& Sörbom, 2007), was used to test and compare the predicted factor model (consisting of six factors) to two other plausible factor models. The factor models are described in Table 3.

The item data violated multivariate normality. As a consequence, the chi-square statistic that is normally used to test model fit will be inflated. In these circumstances, Jöreskog, and Sörbom (2007) recommend testing model fit with a chi-square statistic that corrects for the inflation. The SatorraBentler chi-square provides such a statistic and was therefore used to derive fit statistics for all the factor models.

Five fit statistics were used to evaluate model fit: the Satorra-Bentler chi-square divided by its degrees of freedom $\left(\chi^{2} / d f\right)$ (Kline, 2005), the Comparative Fit Index (CFI) (Hu \& Bentler, 1999), the Non-Normed Fit Index (NNFI) (Hu \& Bentler, 1999), the Standardised Root Mean square Residual (SRMR) (Bentler, 1990), and the Root Mean Square Error of Approximation (RMSEA) (Browne \& Cudeck, 1993; Steiger, 1990). Each of the fit statistics evaluates model fit from a slightly different perspective. The suggested criteria for a good fit is a $\chi^{2} / d f$ statistic less than or equal to 3 (Kline, 2005), a CFI and NNFI value greater than or equal to .9 (Benet-Martínez \& Karakitapoglu-Aygun, 2003), an SRMR less than or equal to .1 (Marsh \& Hau, 2004) and an RMSEA less than or equal to .08 or a $90 \% \mathrm{Cl}$ for RMSEA that encompasses .08 (Benet-Martínez \& Karakitapoglu-Aygun, 2003). 


\section{RESULTS}

The fit statistics for the factor models are reported in Table 4. The predicted model consisting of six correlated factors (Model 1a) was tested first, and was found to fit the data better than an alternative version of the model in which the factors were uncorrelated (Model $1 \mathrm{~b}$ ). The removal of Item 21 from Model 1a, the lowest loading item, produced a better fitting model (Model 1c) that reached threshold for all five fit statistics. Four additional factor models (Models $2 \mathrm{a}$ to $3 \mathrm{~b}$ ) were tested but did not fit the data as well as Model 1c. The correlations among the six factors in Model $1 \mathrm{c}$ are reported in Table 5.

The high correlations between some of the factors within Model 3c (e.g., $r=.909$ between legal and moral) suggests that while the six constructs are conceptually distinct, they might load on a higher order factor. Hence, a final model (Model 4) was examined in which the three highest correlated factors (moral, medical, and legal) were indicated by a higher order factor, while the glamour and economic factors were not indicated by a higher order factor. This model was not found to be a better fit than Model 3c.

Correlations between each of the six of the DDDS factors and locus of control were examined, since the internalisation discourses that limit agency (e.g., medical discourse) should be associated with low levels of internal locus of control, while other discourses that provide increased agency (e.g., economic) might be associated with increased levels of internal locus of control. Only significant correlations were found between with the internal items of the LCBS and the medical $(r=.296, p<$ $.001)$ and legal $(r=.146, p=.004)$ scales of the DDDS.

\section{DISCUSSION}

We have described the development of the DDDS, a psychometric instrument proposed to measure the degree to which individuals internalise the dominant discourses regarding drugs in Australia. Construct validity of the scale is supported by the current research, in which the DDDS data was found to be a good fit with the proposed factorial model.

The DDDS could have significant utility in research examining policy debate and development, and also help understand how the internalisation of certain dominant discourses influences drug users' identities and behaviours. Some researchers (e.g., Rodner, 2005; Sonn \& Fisher, 1998) have shown that certain people are resilient to internalising dominant discourses that are pathogenic. Such resilience could be beneficial to drug users' psychological wellbeing. As such, some of the DDDS scales might be useful in studies examining interventions to reduce drug-related stigma.

However, several authors (e.g., Davies, 1997; McCullough \& Andersen, 2013) have noted that the internalised narrative of lost agency through addiction might assist individuals change and addictive behaviour or seeking treatment. Indeed, this understanding of drug use behaviour might be particularly helpful for successful outcomes within 12-step programs (Keene \& Raynor, 1993) and pharmacological interventions. The medical scale of the DDDS could be helpful in matching treatments with individuals' beliefs about the nature of their behaviour.

Contrary to prediction, internalisation of medical discourse was associated with increased internal locus of control. This could be construed as evidence against the validity of the medical discourse scale, or that the concerns about medical discourse limiting agency may be unfounded - or at least 
the relationship is more complex than first thought. Interesting, the economic discourse scale, which was hypothesised to provide individuals with increased agency, was negatively correlated with the medical, moral, legal, and political discourse scales. This could be considered further evidence of construct validity of the DDDS. There is a need for further research into the role of discourse on agency and treatment outcomes.

Since the DDDS was designed to be used among a range of populations, the subject positions within the items were not personalised (excluding items 13 and 19 within economic discourse scale that refer to "I"). Rather, the items refer to "people" and "you". It is possible that individuals who endorsed items in the medical scale, and indeed the other scales, might apply these narratives to others but not themselves. As such, it is recommended that a separate users' form of the DDDS be developed in which the subject positions within the items are personalised. This form could be compared with the DDDS to better understand the processes inherent to the internalisation of dominant discourse.

While a users' form of the DDDS would have limited applicability in general settings, it might have greater utility in treatment settings. Such a form of the DDDS might also consider the more addiction-specific narratives that medical discourse encompasses, such as the brain disease narrative that has become so salient in addiction research and treatment (Hammer et al., 2013) . This form would necessarily exclude the glamour discourse since it only provides a subject position for celebrities. The present research also furthers understanding of the structure of discourse. Despite medical, moral, legal and political discourse providing space for pathological narratives of drug use, the data did not support a single pathological discourse latent factor. This suggests that the four discourses are discrete and supports the way in which discourse is generally conceptualised (Burr, 2003; Dingelstad et al., 1996). However, this research was conducted on a clinical sample seeking treatment. Further research should examine the DDDS, or other quantitative measures of discourse, using non-clinical samples.

Given the cultural-specificity of discourse, the validity of the DDDS might be limited outside of Australia. Nonetheless, there is significant cultural overlap between Australia and some other Western countries such as the USA and the UK. Consequently, to some the dominant discourses that the DDDS measures might be generalisable.

In conclusion, the DDDS is a unique tool that has been shown to have some validity. We are not aware of any other psychometric instruments that have been developed to examine dominant discourses.

\section{ACKNOWLEDGEMENT}

We would like to acknowledge the psychometric input in the development of the DDDS from Associate Professor Leigh Smith. 


\section{REFERENCES}

Ahern, J., Stuber, J., \& Galea, S. (2007). Stigma, discrimination and the health of illicit drug users. Drug Alcohol Dependence, 88(2-3), 188-196. doi: 10.1016/j.drugalcdep.2006.10.014

Anderson, J. C., \& Gerbing, D. W. (1991). Predicting the performance of measures in a confirmatory factor analysis with a pretest assessment of their substantive validities. Journal of Applied Psychology, 76, 732-740.

Barratt, M. (2012). Beyond Internet as Tool: A Mixed-Methods Study of Online Drug Discussion. (PhD), Curtin University.

Beatch, R., Bedi, R. P., Cave, D., Domene, J. F., Harris, G. E., Haverkamp, B. E., \& Mikhail, A. M. (2009). Counselling psychology in a Canadian context: Report from the executive committee for a Canadian understanding of counselling psychology

Benet-Martínez, V., \& Karakitapoglu-Aygun, Z. (2003). The interplay of cultural values and personality in predicting life-satisfaction: Comparing Asian- and European-Americans. Journal of Cross-Cultural Psychology, 34, 38-61.

Bentler, P. M. (1990). Comparative fit indexes in structural models. Psychol Bull, 107(2), 238-246.

Bright, S. J., Bishop, B., Kane, R., Marsh, A., \& Barratt, M. (2013). Kronic Hysteria: Exploring the intersection between Australian synthetic cannabis legislation, the media, and drug-related harm. International Journal of Drug Policy, 23, 231-237.

Bright, S. J., Kane, R., Marsh, A., \& Bishop, B. (2013). Psychometric Properties of the Locus of Control of Behaviour Scale (LCBS) administered to Australian's seeking Alcohol and Other Drug (AOD) treatment. Australian Psychologist, 48, 172-177.

Bright, S. J., Marsh, A., Bishop, B., \& Smith, L. M. (2008). What can we say about substance use? Dominant discourses and narratives emergent from Australian media. Addiction Research \& Theory, 16, 135-148.

Browne, M. W., \& Cudeck, R. (1993). Alternative ways of assessing model fit. In K. A. Bollen \& J. S. Long (Eds.), Testing Structural Equation Models (pp. 136-162). Beverly Hills, CA: Sage.

Burr, V. (2003). Social Contrsuctionism. New York: Routledge.

Cherryholmes, C. H. (1992). Notes on pragmatism and scientific realism. Educational Researcher, 21(6), 13-17.

Craig, A. R., Franklin, J. A., \& Andrews, G. (1984). A scale to measure locus of control behaviour. British Journal of Medical Psychology, 57, 173-180.

Davies, J. B. (1997). Conversations with Drug Users: A Functional Discourse Model: The Derivation of a Typology of Drug Discourse; and an Empirical Study of Its Predictive Usefulness. Addiction Research, 5, 53-70.

Dingelstad, D., Gosden, R., Martin, B., \& Vakas, N. (1996). The social construction of drug debates. [Review]. Soc Sci Med, 43(12), 1829-1838.

Duff, C. (2004). Drug use as a 'practice of the self': is there any place for an ethics of moderation' in contemporary drug policy? International Journal of Drug Policy, 15, 385-393.

Elliott, A. J., \& Chapman, S. (2000). 'Heroin hell their own making': construction of heorin users in the Australian press 1992-97. Drug and Alcohol Review, 19, 191-201.

Fraser, S., \& Moore, D. (2008). Dazzled by unity? Order and chaos in public discourse on illicit drug use. Soc Sci Med, 66(3), 740-752. doi: 10.1016/j.socscimed.2007.10.012

Hammer R, Dingel M, Ostergren J, Partridge B, McCormick J, \& Koenig B A. (2013). Addiction: Current criticism of the brain disease paradigm. AJOB Neuroscience, 4, 27-32.

Hammer R, Dingel M J, Ostergren J E, Nowakowski K E, \& Koenig B A. (2012). The experience of addiction as told by the addicted: incorporating biological understandings into self-story. Culture, Medicine and Psychiatry, 36, 712-734.

Hogg, M. A., \& Turner, J. C. (1987). Intergroup behaviour, self-stereotyping and the salience of social categories. British Journal of Social Psychology, 26, 325-340.

Hu, L. T., \& Bentler, P. (1999). Cut off criteria for fit indexes in covariance structure analysis: Conventional criteria versus new alternatives. Structural Equation Modeling, 6, 1-55. 
Jöreskog, K., \& Sörbom, D. ( 2007). LISREL 8.8. Chicago: Scientific Software.

Keene, J., \& Raynor, P. (1993). Addiction as a 'soul sickness': The influence of client and therapist beliefs. Addiction Research, 1, 77-87.

Kline, R. B. (2005). Principles and practice of structural equation modeling. New York: Guilford Press.

Lancaster, K., \& Ritter, A. (in press). Examining the construction and representation of drugs as a policy problem in Australia's National Drug Strategy documents 1985 to 2010. International Journal of Drug Policy.

Lawrence, G., Bammer, G., \& Chapman, S. (2000). 'Sendind the wrong signal': Analysis of print media reportage of teh ACT heroin presciption trial proposal, August 1997. Australian and New Zealand Journal of Public Health, 24, 254-264.

Marsh, H. W., \& Hau, K.-T. (2004). In search of golden rules: Comment on hypothesis-testing approaches to setting cutoff values for fit indexes and dangers in overgeneralizing $\mathrm{Hu}$ and Bentler's (1999) findings. Structural Equation Modeling: A Multidisciplinary Journal, 11, $320-$ 341.

McCullough, L., \& Andersen, M. (2013). Agency lost and recovered: A social constructionist approach to smoking addiction and recovery. Addiction Research \& Theory, 21, 247-257.

Moore, D. (2004). Drugalities: The generative capabilities of criminalized 'drugs'. International Journal of Drug Policy, 15, 419-426.

Moore, D. (2008). Erasing pleasure from public discourse on illicit drugs: on the creation and reproduction of an absence. [Research Support, Non-U.S. Gov't]. Int J Drug Policy, 19(5), 353-358. doi: 10.1016/j.drugpo.2007.07.004

Mugford, S. (1991). Controlled drug use among recreational users. In N. Heather, W. Miller \& R. Greeley (Eds.), Self control and the addictive behaviours. NSW, Australia: Maxwell Macmillan.

Murphy, K. R., \& Davidshofer, C. O. (2005). Psychological testing : principles and applications (6th ed.). Upper Saddle River, N.J.: Pearson Prentice Hall.

Nightingale, D. J., \& Cromby, J. (Eds.). (1999). Social constructionist psychology: A critical analysis of theory and practice. Buckingham, UK: Open University Press.

Oppenheim, A. N. (1992). Questionnaire design, interviewing and attitude measurement (New ed.). London, UK: Printer Publishers.

Parker, I. (Ed.). (1998). Social Constructionism, discourse and realism. London, UK: Sage.

Rodner, S. (2005). "I am not a drug abuser, I am a drug user": A discourse analysis of 44 drug users' construction of identity. Addiction Research and Theory, 13, 333-346.

Room, R. (2006). The dangerousness of drugs. [Review]. Addiction, 101(2), 166-168. doi: 10.1111/j.1360-0443.2006.01315.x

Sonn, C., \& Fisher, A. (1998). Sense of community: Community resilient responses to oppression and change. Journal of Community Psychology, 26, 457-471.

Steiger, J. H. (1990). Structural model evaluation and modification: An interval estimation approach. Multivariate Behavioral Research, 25, 173-180.

Stevens, A. (2007). when two dark figures collide: Evidence and discourse on drug-related crime. Critical Social Policy, 27, 77-99.

Stevens, A., \& Ritter, A. (in press). how can and do empirical studies influence drug policies? Narratives and complexity in the use of evidence in policy making. Drugs: Education, Prevention and Policy.

Teyber, E. (1997). Interpersonal process in psychotherapy: A relational approach. CA: Brooks/Cole Publishing.

Yalom, I. (2002). The gift of therapy: Reflections on being a therapist. London: Piatkus. 


\section{Australian Dominant Drug Discourses Scale}

\section{Economic Discourse Items}

1. People are free to choose what drugs they buy

7. Paying for drugs is like paying to see a movie

13. Spending money on drugs is my choice

19. I should be able to spend my money on drugs if I want to

\section{Medical Discourse Items}

2. It is important that you listen to your doctor

8. Doctors know what is best for drug users

14. People who use drugs need to seek treatment

20. People who use drugs are unwell

25. Drug use kills

\section{Moral Discourse Items}

3. People who use drugs lie

9. Drug use causes you to betray other people

15. Drug users are irresponsible

21. Using drugs is wrong

26. Drug users are untrustworthy

\section{Legal Discourse Items}

4. Laws are an effective way of stopping people from using drugs

10. You shouldn't use drugs because they're illegal

16. Drug use leads to crime

22. Drug users should be punished

\section{Political Discourse Items}

5. It's the governments job to protect us from drugs

11. Drug use is a big problem that we need to fix

17. Drug use needs to be regulated

23. Only the minority use drugs

27. Drug use harms society

Glamour Discourse Items

6. Supermodels use drugs

12. It's okay for famous people to use drugs

18. Drugs are intriguing

24. Most rock stars use drugs 
TABLES

Table 1. Initial item set that was developed

Medical Discourse

1. People who use drugs are unwell

2. Drug use makes people unwell

3. Drug use is spreading like a plague

4. Doctors know what is best for drug users

5. People who use drugs need to seek treatment

6. Drug use is unhealthy

7. People who use drugs are unwell

8. It is important that you listen to your doctor

9. Drug use puts you at risk of HIV

10. Unhealthy people use drugs

11. Drugs are dangerous

12. Drug use kills

Legal Discourse

1. Drug use leads to crime

2. Punishment for drug dealers is not harsh enough

3. People who use drugs are criminal

4. Drug users should be punished

5. Laws are an effective way of stopping people from using drugs

6. You shouldn't use drugs because they're illegal

7. Drug dealers prey on the weak

8. Drugs should be prohibited

\section{Moral Discourse}

1. People who use drugs are lazy

2. Using drugs is wrong

3. People who use drugs are stupid

4. People can't control their own drug use

5. It is not normal to use drugs

6. Drug users are untrustworthy

7. People who use drugs lie

8. Normal people don't use drugs

9. Drug use causes you to betray other people

10. People who use drugs steal

11. Drugs take control of people's lives

12. People who use drugs can't be trusted

13. Drug users are irresponsible

14. People who use drugs don't know when to stop

15. Drug use destroys families

16. Drugs should be condemned

17. Successful people don't use drugs 
Political Discourse

1. Only the minority use drugs

2. Drug use harms society

3. Drugs are a threat to society

4. It's the governments job to protect us from drugs

5. Drug use is a big problem that we need to fix

6. Drug use needs to be regulated

7. Drugs cost taxpayers a lot of money

8. We need to control people's drug use

\section{Glamour Discourse}

1. Most rock stars take drugs

2. It's okay for famous people to use drugs

3. Drug use makes people interesting

4. Drugs are fascinating

5. Supermodels use drugs

6. Drug are intriguing

7. Drugs are alluring

\section{Economic Discourse}

1. People are free to choose what drugs they buy

2. Paying for drugs is like paying to see a movie

3. I like some drugs, but not others

4. Spending money on drugs is my choice

5. I should be able to spend my money on drugs if I want to

6. I make an informed choice about whether or not I use particular drugs

7. Drugs are just another way of having fun

Table 2. Description of dimensions used in the substantive validity analysis.

\begin{tabular}{lll}
\hline Discourse & Subject Positions & Narrative \\
\hline Economic & Consumer, Dealer & Drugs are commodities \\
Medical & Sick, Expert & Drugs are pathogens \\
Moral & Deviant, Righteous & Using drugs is wrong as they deprave \\
Legal & Criminal, Law enforcer & Using drugs is against law \\
Political & Politician, Constituents & Governments must protect citizens from drugs \\
Glamour & Celebrities & Famous people who use drugs are interesting \\
& & \\
\hline
\end{tabular}


Table 3. Description of the three models

\begin{tabular}{|c|c|c|}
\hline Factor model & $\begin{array}{l}\text { Number of } \\
\text { factors }\end{array}$ & Names of factors \\
\hline $\begin{array}{l}\text { Model 1a (correlated factors) } \\
\text { Model 1b (uncorrelated factors) }\end{array}$ & 6 & $\begin{array}{l}\text { Medical, moral, political, legal, } \\
\text { economic, glamour. }\end{array}$ \\
\hline $\begin{array}{l}\text { Model 2a (correlated factors) } \\
\text { Model 2b (uncorrelated factors) }\end{array}$ & 2 & $\begin{array}{l}\text { Pathological (as measured by the } \\
\text { medical, moral, political, and legal } \\
\text { items) and alternative (as } \\
\text { measured by the economic and } \\
\text { glamorous items) }\end{array}$ \\
\hline $\begin{array}{l}\text { Model 3a (correlated factors) } \\
\text { Model 3b (uncorrelated factors) }\end{array}$ & 3 & Pathological, economic, glamour \\
\hline Model 4 & 7 & $\begin{array}{l}\text { One higher order factor } \\
\text { (pathological) driving three of the } \\
\text { six lower order correlated factors } \\
\text { (medical, moral, legal); there is no } \\
\text { higher order factor driving } \\
\text { economic and glamour }\end{array}$ \\
\hline
\end{tabular}


Table 4. Fit statistics for CFAs of DDDS

\begin{tabular}{|c|c|c|c|c|c|c|}
\hline Model & Description & $\chi^{2} / \mathrm{df}$ & $\begin{array}{l}\text { Comparative } \\
\text { Fit Index } \\
\text { (CFI) }\end{array}$ & $\begin{array}{l}\text { Non-normed } \\
\text { Fit Index } \\
\text { (NNFI) }\end{array}$ & $\begin{array}{l}\text { Standardised Root } \\
\text { Mean Square } \\
\text { Residual (SRMR) }\end{array}$ & $\begin{array}{l}\text { Root Mean Square Error of } \\
\text { Approximation } \\
\text { (RMSEA) }\end{array}$ \\
\hline $1 a$ & Six correlated factors & $1038.52 / 309=3.36$ & .913 & .901 & .080 & .080 (90\% Cl: .075, .085) \\
\hline $1 b$ & Six uncorrelated factors & $1921.24 / 324=5.94$ & .808 & .792 & .197 & .116 (90\% Cl: .111, .121) \\
\hline 1c & $\begin{array}{l}\text { Six correlated factors } \\
\text { without Item } 21\end{array}$ & $873.746 / 309=2.83$ & .914 & .901 & .078 & .075 (90\% Cl: .069, .081) \\
\hline $2 b$ & Two uncorrelated factors & $927.11 / 209=4.44$ & .889 & .878 & .111 & .097 (90\% Cl: .090, .103) \\
\hline $3 a$ & Three correlated factors & $849.38 / 206=4.12$ & .904 & .893 & .089 & .092 (90\% Cl: .086, .099) \\
\hline $3 b$ & Three uncorrelated factors & $909.05 / 209=4.35$ & .892 & .881 & .112 & .095 (90\% Cl: .089, .102) \\
\hline
\end{tabular}


Table 5. Correlation Matrix of Latent Variables $(N=370)$

\begin{tabular}{lllllll}
\hline & ECON & MED & MORAL & LEGAL & POLIT & GLAM \\
\hline ECON & 1.000 & & & & & \\
MED & -0.385 & 1.000 & & & & \\
MORAL & -0.246 & 0.880 & 1.000 & & & \\
LEGAL & -0.513 & 0.896 & 0.909 & 1.000 & & \\
POLIT & -0.281 & 0.850 & 0.842 & 0.767 & 1.000 & \\
GLAM & 0.153 & 0.422 & 0.441 & 0.318 & 0.333 & 1.000
\end{tabular}

$p<.001$ for all correlations, except for GLAM and ECOM, where $p=.081$ 